\title{
Comparative analysis of carbon emissions quota calculation and allocation method for coal-fired power plant in China
}

\author{
LIBAO YIN ${ }^{1} \quad$ XINXIN ${ }^{2}$ MENG\&ZHENGYANG ${ }^{2}$ GAO\&SHUO $\mathrm{JI}^{2}$ \\ ${ }^{1}$ Electric Power Research Institute of Guangdong Power Grid ， Guagnzhou ,China \\ ${ }^{2}$ North China Electric Power University,Baoding,China
}

KEYWORD: Coal-fired power plant; $\mathrm{CO}_{2}^{2}$;Carbon trading;Quota;Pilot cities

\begin{abstract}
With the rapid development of economic globalization and the improvement of people's living standards, and the impact of global warming gradually strengthened. The emissions and trading scheme of carbon dioxide has been widespread concern at home and abroad. The establishment of carbon emissions system and the accounting of the quota in the trading process become the key points. In This paper, the present situation of carbon emissions and its trading system is described, and the carbon emission quotas of a power plant is accounted in different calculation methods of domestic carbon emission pilot cities. The results are compared with the actual quota, and then the comparative analysis of the characteristics of the carbon quota accounting methods in different pilot cities is made, to provide references for further improvement of domestic carbon trading market.
\end{abstract}

\section{Introduction}

The current study shows that the main greenhouse gases include carbon dioxide, methane, nitrous oxide, ground-level ozone, HCFCs, ect. Carbon dioxide is the weakest of greenhouse gases, but the emissions is the largest, accounting for $72 \%$ of total greenhouse gas emissions. Besides, the amount of the share of total intensity of radiation of the greenhouse gases is $55 \%$, and degradation time of carbon dioxide in the atmosphere is up to $50-200$ years ${ }^{[1]}$. It is because the greenhouse effect of carbon dioxide is the most outstanding in all of the six greenhouse gases that its emissions and control becomes a problem of common concern at home and abroad.

\section{Current situation analysis of the international emissions trade}

In December 1997, 《Framework Convention» COP3 meeting was held in Tokyo, Japan, and a total of 149 representatives from different countries and regions reach an agreement on 《Kyoto Protocol», which is the first to limit greenhouse gas emissions in the form of regulations in human history $^{[2]}$. From then on, each country has taken a number of measures in many ways, and made positive efforts for greenhouse gas emission reduction. 
Table 1: Key elements for pilot schemes

\begin{tabular}{|c|c|c|c|}
\hline Pilot cities & Industry Coverage & $\begin{array}{c}\text { Quota allocation } \\
\text { method }\end{array}$ & $\begin{array}{l}\text { Quota } \\
\text { allocation } \\
\text { method }\end{array}$ \\
\hline shanghai & $\begin{array}{l}\text { electricity, steel, } \\
\text { chemicals, } \\
\text { building materials, } \\
\text { etc }\end{array}$ & $\begin{array}{c}\text { Free parts of the Carbon } \\
\text { emissions quotas of } \\
\text { 2013-2015 } \\
\text { is given one-time }\end{array}$ & $\begin{array}{l}\text { reference line } \\
\text { method }\end{array}$ \\
\hline Beijing & $\begin{array}{l}\text { Iron and steel, } \\
\text { chemicals, } \\
\text { electricity and heat, } \\
\text { petrochemical,const } \\
\text { ruction etc }\end{array}$ & $\begin{array}{c}\text { Free quota is } \\
\text { distributed each year, } \\
\text { a small number is set } \\
\text { aside for auction of } \\
\text { government }\end{array}$ & $\begin{array}{c}\text { Historical } \\
\text { method }\end{array}$ \\
\hline Tianjin & $\begin{array}{l}\text { Iron and steel, } \\
\text { chemicals, } \\
\text { electricity, heat, } \\
\text { petrochemical etc }\end{array}$ & Mainly for free & $\begin{array}{l}\text { reference line } \\
\text { method }\end{array}$ \\
\hline Shenzhen & $\begin{array}{l}\text { Electricity, } \\
\text { construction } \\
\text { manufacturing } \\
\text { etc }\end{array}$ & $\begin{array}{l}\text { Paid and unpaid,and } \\
\text { Some quotas is reserved } \\
\text { for new entrants }\end{array}$ & - \\
\hline Guangdong & $\begin{array}{l}\text { Electricity, cement, } \\
\text { steel, ceramics, } \\
\text { petrochemicals, } \\
\text { textiles, paper, etc. }\end{array}$ & $\begin{array}{l}\text { Paid and unpaid,and } \\
\text { Some quotas is reserved } \\
\text { for new entrants }\end{array}$ & $\begin{array}{c}\text { Historical } \\
\text { method } \\
\text { and reference } \\
\text { line method }\end{array}$ \\
\hline Hubei & $\begin{array}{l}\text { Iron and steel, } \\
\text { chemicals, cement, } \\
\text { automobile } \\
\text { manufacturing } \\
\text { electricity, etc. }\end{array}$ & $\begin{array}{l}\text { For free, and } 3 \% \text { is for } \\
\text { regulation of carbon } \\
\text { trading market, } 15 \% \text { is } \\
\text { for new entrants }\end{array}$ & $\begin{array}{c}\text { Historical } \\
\text { method } \\
\text { and } \\
\text { benchmarking } \\
\text { method }\end{array}$ \\
\hline Chongqing & $\begin{array}{c}\text { Electric power, } \\
\text { metallurgy, } \\
\text { chemicals, etc. }\end{array}$ & For free & $\begin{array}{l}\text { the emission } \\
\text { factor method }\end{array}$ \\
\hline
\end{tabular}

\section{Analysis of the development process and the status of carbon emissions trading in western country}

In 1999, the EU responded positively to the call of the 《Kyoto Protocol», and it is the first to began to fulfill the emission reduction obligations. The first greenhouse gas and energy trading simulation system EU-ETS (European Union Emission Trade Scheme)in the world is established ${ }^{[3]}$. The European Climate Exchange has become the most important carbon emissions trading venues in the world. The well-known includes voluntary transaction of the Chicago Climate Exchange, the Regional Greenhouse gas Initiative, western climate initiative and the California cap-and-trade system. Australia has reached an agreement with the EU on August 28, 2012. The agreement 
stipulated that the carbon emissions trading system of the two sides will start to be docking on July $1,2015^{[4]}$.

\section{Process and Status analysis for the development of emissions trading in China}

At present, the number of the expected emission reductions and the number of the CERS in China issued by United Nations are all living in the the first place of the world. Besides, the Chinese government has put forward the target in the "five" plan that the carbon emission intensity of per GDP in 2015 is reduced for $17 \%$ compared to that of $2010^{[5]}$. The target is decomposed to different provinces as a binding target ${ }^{[6]}$.

Comparative analysis of different methods in carbon trading pilot cities of China for calculation and distribution of quota

\section{Comparition of trading mechanism in the carbon trading pilot cities}

Carbon emission of the coal-fired power plant, as $\mathrm{CO} 2$ fixed emissions source, is living around $37 \%$ of total emissions stably ${ }^{[7]}$. Currently, the carbon emissions trading markets of the seven pilot cities including Beijing, Shenzhen, Guangdong, Shanghai, Tianjin, Hubei, Chongqing, are all on the line to start the transaction, and the national carbon trading market is planted to be established in about three years.

Take a power plant for an example to calculate the quota in different methods of pilot cities

The basic situation of the power plant

A power plant is taken for an example to calculate the carbon dioxide quota in 2014 in different methods of pilot cities. There are a circulating fluidized bed unit with a capacity of $300 \mathrm{MW}$ and a ultra high pressure coal fired unit with a capacity of $125 \mathrm{MW}$. They are both having been put into operation of the emission facilities (unit) before January 1, 2013. The power generation and carbon dioxide emissions in the power plant from 2009 to 2014 is shown in Table

\begin{tabular}{ccccc}
\multicolumn{3}{c}{ Table 2 } & CO2 emissions of M Plant 2009--2014 \\
\hline & $\begin{array}{c}\text { Total carbon } \\
\text { Year }\end{array}$ & $\begin{array}{c}\text { Power } \\
\text { dioxide } \\
\text { emissions/t }\end{array}$ & generation & \multicolumn{2}{c}{\begin{tabular}{c} 
Emissions \\
\cline { 3 - 5 }
\end{tabular}} & MWh & MWh & MWh \\
\hline 2009 & 2619249.035 & 2707765.90 & 2539884.417 & 0.9673 \\
2010 & 2487288.477 & 2580388.90 & 2420404.797 & 0.9639 \\
2011 & 2351540.264 & 2449444.56 & 2297579.000 & 0.9600 \\
2012 & 2228326.467 & 2325727.95 & 2181532.821 & 0.9581 \\
2013 & 2110348.502 & 2211500.71 & 2074536.261 & 0.9543 \\
2014 & 1998491.116 & 2102143.03 & 1974398.176 & 0.9507 \\
\hline
\end{tabular}

Quotas of $M$ Power plant in 2014 is calculated based on different carbon quota accounting methods in the pilot cities

The carbon emissions quota of the existing facilities in Beijing is calculated based on historical emissions intensity. The average emission intensity of 2009 - 2012 is taken as the standard, and the emission control coefficient of thermal power enterprises was $99.7 \%$ 。 The average carbon dioxide emissions intensity of the power plant for 2009 - 2012 is calculated to be $0.9623 \mathrm{t} / \mathrm{Mwh}$ according to table 2 . 


$$
\begin{aligned}
\mathrm{P} & =(\mathrm{W} \times \mathrm{J}) \times \mathrm{f} \\
& =1974398.176 \times 0.9623 \times 99.7 \% \\
& =1894263.4750 \mathrm{t}
\end{aligned}
$$

Where: $\mathrm{P}$ is Quota amount; $\mathrm{W}$ is power supply quantity; $\mathrm{J}$ is basic emission standard; $\mathrm{f}$ is controlling coefficient.

The emission quota of Shanghai electric power industry is calculated in reference line method. The annual comprehensive carbon emissions standard of the power plant in 2014 year is 0.8177 tons / Mwh, according to the type of power plant units and the installed capacity. The correction coefficient is 1 , according to the power plant performance and annual load rate.

$$
\begin{aligned}
\mathrm{P}=\mathrm{J} \times \mathrm{W} \times \mathrm{m} & =8.177 \times 210214.3039 \times 1 \\
& =1718922.3630 \mathrm{t}
\end{aligned}
$$

Where: $\mathrm{P}$ is annual carbon emission quota; $\mathrm{J}$ is basic emission standard; $\mathrm{W}$ is annual comprehensive power generation; $\mathrm{m}$ is correction coefficient.

The quota for the electric power industry in Guangdong Province is calculated in the reference line method. The power generation capacity of the circulating fluidized bed unit with the capacity of 300MW is $1561059.331 \mathrm{MWh}$, and the reference value is $927 \mathrm{~g} \mathrm{CO} 2 / \mathrm{kWh}$, and annual descending coefficient is 1 . The power generation capacity of the $125 \mathrm{MW}$ ultra high pressure coal-fired unit in 2013 is $650441.388 \mathrm{MWh}$,and the reference value is $965 \mathrm{~g} \mathrm{CO} 2 / \mathrm{kWh}$, and annual descending coefficient is 1 .The capacity correction factor of the two units is 0.9506 and 0.9502 , according to the ratio of annual generating capacity for 2013 and 2014.

For the power generation capacity of the circulating fluidized bed unit with the capacity of 300MW:

$$
\begin{aligned}
\mathrm{P}_{0} & =\mathrm{W} \times \mathrm{J} \times \mathrm{n} \\
& =156105.9331 \times 10^{4} \times 927 \times 10^{-6} \times 1 \\
& =1447101.9998 \mathrm{t} \\
\mathrm{P}_{01} & =\mathrm{P}_{0} \times \mathrm{f} \\
& =1447101.9998 \times 0.9504 \\
& =1375325.7400 \mathrm{t}
\end{aligned}
$$

For the $125 \mathrm{MW}$ ultra high pressure coal-fired unit :

$$
\begin{aligned}
\mathrm{P}_{0}{ }^{\prime} & =\mathrm{W} \times \mathrm{J} \times \mathrm{n} \\
& =627675.9394 \mathrm{t} \\
\mathrm{P}_{02} & =\mathrm{P}_{0}{ }^{\prime} \times \mathrm{f} \\
& =627675.9394 \times 0.9504 \\
& =596543.2128 \\
\mathrm{P} & =\mathrm{P}_{01}+\mathrm{P}_{02} \quad=1375325.7400+596543.2128 \\
& =1971868.9530 \mathrm{t}
\end{aligned}
$$

The free carbon emissions quota in 2014 is:

$1971868.9530 \times 95 \%=1873275.5050 \mathrm{t}$

Where $: P_{0}$ is approved carbon emission quota; $\mathrm{J}$ is reference value; $\mathrm{W}$ is power generation in 2013;n is descending coefficient; $\mathrm{P}_{01}$ is actual carbon emission quota for the $300 \mathrm{MW}$ circulating fluidized 
bed unit ; $\mathrm{P}$ is the total quota of the power plant in 2014; $\mathrm{P}_{02}$ is actual carbon emission quota for the $125 \mathrm{MW}$ ultra high pressure coal-fired unit. $\mathrm{f}$ is correction factor.

The quota is calculated and allocated comprehensively using the historical method and benchmark method in Hubei province. The adjustment factor is 0.9192. The average historical emissions from 2009 to 2011 is $2486025.926 t$, and the average power generation is 2579199.792 $\mathrm{kWh}$ from 2009 to 2011.Because the actual power output of the power plant in 2014 exceeded 50\% of the annual average, additional quota is required to the power plant as an expost adjustment. The benchmark value is 91.931 tons /Mwh.

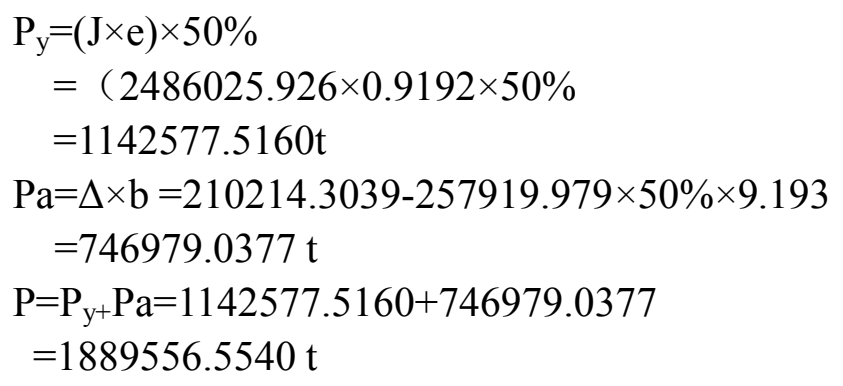

Where $: \mathrm{P}_{\mathrm{y}}$ is is approved carbon emission quota; $\mathrm{J}$ is historical base of emissions; $\mathrm{e}$ is adjustment coefficient; $\mathrm{Pa}$ is additional quota; $\Delta$ is excess capacity; $\mathrm{b}$ is benchmark value; $\mathrm{P}$ is the actual quota.

The quota for power industries in Tianjin is calculated in the reference method. The average value in 2013 is decided by the carbon dioxide emissions under normal operating conditions in the 2009 -2012. The unit of the power plant belongs to the existing facilities, and the baseline level of 2014 is determined to be $0.9604 \mathrm{t} / \mathrm{Mwh}$, which reduced by $0.2 \%$ of the 2013 annual benchmark value. The power plant is given $90 \%$ of the average power supply of carbon dioxide emissions according to the benchmark level.

$\mathrm{P}_{\text {basic }}=\mathrm{J} \times \mathrm{W} \times 90 \%$

$=0.9604 \times 2515831.832 \times 90 \%$

$=2174584.4020 \mathrm{t}$

$\mathrm{P}_{\text {adjustment }}=\mathrm{J} \times \mathrm{W}-\mathrm{P}_{\text {basic }}$

$=0.9604 \times 2102143.039-2174584.4020$

$=-155686.2273 \mathrm{t}$

$\mathrm{P}=\mathrm{P}_{\text {basic }}+\mathrm{P}_{\text {adjustment }}$

$=2174584.4020-155686.2273$

$=2018898.1750 \mathrm{t}$

Where : $\mathrm{P}_{\text {basic }}$ is the basic quota; $\mathrm{P}_{\text {adjustment }}$ is the quota for adjustment; $\mathrm{P}$ is the actual quota; $\mathrm{J}$ is the reference level in 2014; $\mathrm{W}$ is the average power generation.

The greenhouse gases approved in Chongqing city contain a total of six major greenhouse gases. The quota of carbon emissions in Chongqing is calculated in the emission factor method. For the power plant :

$$
\begin{aligned}
\mathrm{P} & =\mathrm{P}_{\text {direct }} \\
& =\mathrm{AD}_{\mathrm{i}} \times \mathrm{EF}_{\mathrm{iCO} 2}+\mathrm{AD}_{\mathrm{i}} \times \mathrm{EF}_{\mathrm{iN}_{2} \mathrm{O}} \times \mathrm{GWPN}_{2} \mathrm{O}
\end{aligned}
$$

Where $: \mathrm{P}$ is the $\mathrm{P}$ is the total quota; $\mathrm{P}_{\text {direct }}$ is the quota for direct emission; $\mathrm{AD}_{\mathrm{i}}$ is the type of the fuel; $\mathrm{EF}_{\mathrm{iCO} 2}$ is the carbon dioxide emission factor of fuel $\mathrm{i} ; \mathrm{EF}_{\mathrm{iN} 2 \mathrm{O}}$ is the nitrous oxide emission factor of fuel i ; $\mathrm{GWP}_{\mathrm{N} 2 \mathrm{O}}$ is the Global Warming Potential value of nitrous oxide.

The corresponding emission factors can be get from the appendix B, appendix $\mathrm{C}$ of 《 Guidelines for carbon emissions accounting and reporting of industrial enterprises in 
Chongqing(Trial) 》. The result that $\mathrm{GWPN}_{2} \mathrm{O}=310$ can be get from the appendix $\mathrm{A}$ of $《$ Guidelines for carbon emissions accounting and reporting of industrial enterprises in Chongqing(Trial) 》, and the total quota is $2217615.4325 \mathrm{t}$.

\section{Conclusions}

According to the calculation method for carbon emissions quota of power industry in various cities, the results for the carbon emissions quota of the power plant calculated in 2014 is shown in Table 3 .

$$
\Delta=\mathrm{P}_{\text {actual }}-\mathrm{P}_{\text {calculated }} \quad \theta=\left(\mathrm{P}_{\text {actual }} / \mathrm{P}_{\text {calculated }}\right) \times 100 \%
$$

Where $: \Delta$ is the amount of quota deviation; $\theta$ is the $\mathrm{P}_{\text {actual }}$ is the actual quota; $\mathrm{P}_{\text {calculated }}$ is the calculated quota.

\begin{tabular}{lcccc} 
Table 3 Comparison of & Calculation & $\mathrm{P}_{\text {calculated }}$ & $\mathrm{P}_{\text {actual }}$ & Deviation rate \\
\cline { 2 - 5 } actual quota for carbon & method & $\mathrm{t}$ & $\mathrm{t}$ & $\%$ \\
\cline { 2 - 5 } & actual & 1998491.117 & - & - \\
Beijing & 1894263.475 & 104227.6417 & 5.2153 \\
Shanghai & 1718922.363 & 279569.7537 & 14.7587 \\
& Guangdong & 1873275.505 & 125217.6117 & 7.2846 \\
& Tianjin & 2018898.175 & -20404.0583 & 1.0892 \\
& Hubei & 1889556.554 & 108938.5627 & 5.3959 \\
& Chongqing & 2217615.433 & -219119.315 & 11.5963354 \\
\hline
\end{tabular}

calculation quotas and emissions

The carbon emissions quota of the plant in 2014 calculated in the method of Tianjin and Chongqing is higher than that of the actual quotas. Maybe, the selection of the baseline values in Chongqing city are different from several other cities and the quota for adjustment is directly included in the existing capacity quota. The carbon emission is defined as the emissions of greenhouse gases to the atmosphere in Tianjin city, which could result in the deviation of the amount of the relative higher than the actual amount of the quota. The rate of deviation ranges small to large: Tianjin $<$ Guangdong $<$ Beijing $<$ Hubei $<$ Chongqing $<$ Shanghai. More detailed and accurate basis for the adjustment of the quota is provided in Tianjin, and the average carbon dioxide emission intensity of 2009 - 2012 is taken as the reference value. In Guangdong Province, the pure coal-fired generator group of the unit type and size are specified in detail for the conversed baseline values of the carbon dioxide emissions quota, which would make a good demonstration for improving the accuracy and precision of carbon quota accounting. The rate of the load factor is determined according to the performance of the power plant and the annual load rate in shanghai, but the detailed reference standards have yet been given.

\section{Reference:}

[1]Ang B W, Zhang F Q, Choi K H. Factorizing changes in energy and environmental indicators 
through decomposition[J]. Energy, 1998, 23(6): 489-495.

[2] Feng Li, Wei Wei China's carbon emissions trading platform research [D] Xi'an: Northwestern University, 2012.

[3] Wei Dong Li, Han Honglin, Lu Tao Chinese coal-fired power plants carbon dioxide emissions calculation methods. Beijing: Beijing Jiaotong University, 2014.

[4]Clive L. Spash.The Brave New World of Carbon Trading[J].New Political Economy,2010,15(2):169-195.

[5]Shi-Chun Xu, Zheng-Xia He, Ru-Yin Long.Factors that influence carbon emissions due to energy consumption in China: Decomposition analysis using LMDI[J].Applied Energy, 2014,(127):182-193.

[6] Qishao Zhou, Fu Kun Comparative Analysis of low-carbon economy in the provincial carbon emissions accounting method [J]. Wuhan University, 2013,66 (2), 85-92.

[7] Zhan Zhi steel, Zhude Chen, Xu Qisheng. Absorption Regeneration ionic liquid mixture [J] Guangdong Electric Power, 2014,27 (11), 41-46 - .CO2 in liquid amine. 